\title{
Regulating Ethical Failures: Insights from Psychology
}

\author{
David De Cremer \\ Ann E. Tenbrunsel \\ Marius van Dijke
}

\begin{abstract}
Ethical failures are all around. Despite their pervasiveness, we know little how to manage and even survive the aftermath of such failures. In this paper, we develop the argument that as business ethics researchers we need to zoom in more closely on why ethical failures emerge, and how these insights can help us to be effective ethical leaders that can increase moral awareness and manage distrust. To succeed in this scientific enterprise, we advocate the use of a behavioral business ethics approach that relies on insights from psychology.
\end{abstract}

KEY WORDS: behavior business ethics, leadership, moral awareness, trust

\section{Introduction}

The numerous international scandals in business such as those at AIG, Tyco, WorldCom, Enron, and Ahold have made all of us concerned about the emergence of unethical and irresponsible behavior in organizations. It seems that no matter where we look today, the erosion of ethics and basic moral principles of right and wrong have taken us to the point where trust in our institutions and the very systems that make our society work are in imminent danger of oblivion. These observations make clear that ethical failures have become an important reality for corporations, organizations, and societies at large and as a result there is a growing concern on how to manage and regulate such failures (De Cremer, 2009, 2010; Tenbrunsel and Smith-Crowne, 2008).

Responding to these observations, in 2009 (October 21-22), the authors of this article organized a 2-day conference on the topic of "On understanding the psychology of regulating ethical failures". The conference took place at Rotterdam School of Management, the Netherlands and the formal organization was in the hands of the Erasmus Centre of Behavioural Ethics, which in the same week of the conference was officially opened by the Erasmus University Rotterdam. The conference was a great success and received also much media attention in the Netherlands. Because of the necessity of understanding better how to deal with ethical failures, a special issue in Journal of Business Ethics was agreed upon.

In this special issue, we aim to zoom in on the art of regulating ethical failures by providing a psychological account of how leadership, rules and the management of distrust may operate in the case of ethical failures. Although many organizations attempt to prevent the emergence of unethical decisions and actions, it is clear that these events will nevertheless occur (De Cremer et al., 2010b). For this reason, policy makers and organizations should be aware and possess the necessary knowledge on how to remedy emerging ethical failures, that is, how to deal with things when they have gone wrong. One of the more popular responses is to develop formal programs in which leaders are educated, rules are implemented and the emerging distrust is tackled (Schwartz, 2001; Weaver, 2001). The idea underlying such formal programs is to increase awareness of moral principles and create improved ethical climates, often through interventions implemented at the leadership level. Codes of conducts, rules and integrity officers are popular tools that these formal programs employ, which not only serve to increase moral awareness and improve ethical cultures but also can be mechanisms which attempt to restore trust (Adams et al., 2001). A problem with this approach is, however, that leaders, rules and trust management are not a perfect route to success when it comes down to promoting integrity and 
moral awareness (Ludwig and Longenecker, 1993). We argue that the reason for this lack of success is that we do not understand why these work and, conversely, when they might not. In other words, to understand how to regulate ethical failures effectively, we need to understand the psychological reality of ethical leadership, rules and trust management in terms of moral awareness and how best to deal with the management of the failure itself.

To address these issues, we focus on the recent emerging field of behavioral business ethics, which uses insights from psychology to arrive at a better understanding of ethical behavior in business and organizations (De Cremer and Tenbrunsel, forthcoming). Business ethics generally deals with evaluating whether practices of employees, leaders and organizations as a whole can be considered morally acceptable (Ferrell et al., 2008). To date, however, most discussions about changing the system, and how the individuals involved need to structure their work, are inspired by normative theories that provide prescriptive tools on how to tackle the emergence of ethical failures. Rather than examining and illustrating how moral and ethical people should behave - as the prescriptive approach in business ethics advocates (Trevino and Weaver, 1994) - in this issue we zoom in on how ethical failures could be managed and why this management sometimes may work and sometimes not. More specifically, the aim of this series of papers is to promote our insights into understanding the psychological processes that shape the potential influence of leaders, rules and trust restoration, tools that are often used in the management of ethical failures. To achieve this knowledge, we adopt a descriptive approach which examines how individuals make actual decisions and engage in real actions when they are faced with ethical dilemmas. A major assumption of the behavioral business ethics approach is that many of the ethical failures witnessed in society and organizations are not the result of so-called bad apples (some are, but the majority of such events are not) but come from a much wider set of individuals (Bazerman and Banaji, 2004). Research on this issue suggests that all of us may commit unethical behaviors, given the right circumstances. Treviño et al. (2006, p. 952) recently defined behavioral ethics as a notion that "refers to individual behavior that is subject to or judged according to generally accepted moral norms of behavior." Tenbrunsel and Smith-Crowne (2008, p. 548) interpret this definition as saying that "behavioral ethics is primarily concerned with explaining individual behavior that occurs in the context of larger social prescriptions." Because of its focus on the actual behavior of the individual (i.e., advocating thus a descriptive approach rather than a prescriptive one), it becomes clear that research in behavioral ethics largely draws from work in psychology. The field of psychology is indeed referred to as the scientific study of human behavior and thought processes (Morris and Maisto, 2001). As such, it has been argued that psychological insights will be necessary to promote our understanding of why it is the case that good people sometimes can do bad things as well (Messick and Tenbrunsel, 1996; Dinehart et al., 2001). Along the same lines of reason, Bazerman and Banaji (2004, p. 1150) recently also noted "that efforts to improve ethical decision making are better aimed at understanding our psychological tendencies." (see also Messick and Bazerman, 1996).

It thus stands to reason that a behavioral ethics approach is well-suited to offer an understanding of how to promote ethical behavior in organizations and business. Indeed, an approach that focuses on the psychology of normative behavior may help to uncover the motives of people with respect to ethics. We would like to note immediately, however, that looking at behavior is just one step and that we need to also take the second step of understanding the processes motivating the behavior. That is, the same behavior may be motivated by different motives and judgments or different behaviors can be regulated by the same motive. Thus, we also need to understand why specific behaviors are displayed, and therefore we need to understand the psychological underpinnings of behavior relevant to ethics in greater detail; an aim that the present special issue aims to tackle. In what follows, we briefly describe the papers of this special issue that provide this understanding utilizing three general themes: (1) ethical leadership, (2) moral awareness, and (3) management of distrust.

\section{Ethical leadership}

In the scientific literature, ethical leadership is defined as "the demonstration of normatively 
appropriate conduct through personal actions and interpersonal relationships, and the promotion of such conduct to followers through two-way communication, reinforcement, and decision-making" (Brown et al., 2005, p. 120). A vast amount of recent research has revealed many benefits of this leadership style, particularly its positive effects on employees' leader evaluations and ethical and prosocial behaviors (Brown et al., 2005; Mayer et al., 2009; Walumbwa and Schaubroeck, 2009). Ethical leaders have thus been argued to be important for promoting ethical working climates and making salient the moral standards employees should use (Kanungo, 2001). Although ethical leaders are equipped with the means necessary to regulate, monitor and promote ethical awareness and climates after unethical behaviors have emerged, it is also a fact that those leaders are not perfect all the time. Thus, leadership itself may sometimes also fail in directing ethics within organizations and business because they suffer from biases that can prevent them from making the right and accurate decisions. In this special issue, a series of papers zoomed in on the psychological workings of ethical leadership. Specifically, these papers look at the effectiveness of various ethical leader types and under which circumstances they sometimes may be less effective.

The paper by Mayer, Kuenzi, and Greenbaum empirically examine why ethical leadership leads to less employee misconduct. Drawing on theory and research on ethical leadership and ethical climate, they examine whether ethical climate explains (i.e., mediates) the relationship between ethical leadership and employee misconduct. They find support for these ideas in large scale field study in a variety of organizations.

Stouten, Baillien, Van den Broeck, and Euwema focus on one specific type of employee misconduct: bullying of coworkers. Bullying is a highly impactful deviant action that affects employees' work experiences and even their mental and physical health. Because hierarchical influence is often necessary to decrease bullying, ethical leaders may be particularly effective in decreasing bullying. Stouten and colleagues show that ethical leadership is negatively associated with workplace bullying because this type of leadership tackles one of the most important antecedents of bullying: the design of the work environment.
Hoogervorst, De Cremer, and van Dijke zoom in on one core aspect of ethical leadership, that is, leaders' disapproval of unethical follower behavior (UFB). They show in a laboratory experiment that holding leaders accountable for their actions makes them disapprove of UFB. However, this effect of accountability is inhibited when leaders personally benefit from UFB. Moreover, in a subsequent study they also show that followers can accurately predict the conditions that make leaders most likely to disapprove of UFB, suggesting that followers can get away with unethical behavior in many situations because of these predictive abilities.

Finally, Giessner and van Quaquebeke analyze a question that psychological theories of ethical leadership have thus far left unanswered: Normatively appropriate conduct is central to ethical leadership, but what do people actually consider normatively appropriate and, hence, what are the standards for ethical leadership? They draw upon Relational Models Theory (Fiske, 1992), which differentiates between four types of relationships: communal sharing, authority ranking, equality matching, and market pricing. They describe how each of these relationship models dictates a distinct set of normatively appropriate behaviors. They finally argue that perceptions of unethical leadership can result from a mismatch between leader's and follower's relational models, diverging views about the behavioral expression of the same relational model, or a violation of a previously agreed upon relational model.

\section{Moral awareness}

Remedies for ethical failures often focus on increasing moral awareness. When making decisions it is important that people are aware of the moral implications of their actions. As Jones (1991) puts it, "for the moral decision-making process to begin, a person must recognize the moral issue" (p. 380). An important assumption of theoretical models advocating this idea is that they describe moral awareness as a rational process. That is, people are able to interpret moral dilemmas in a conscious manner in which cognitive corrections can be applied. Research on the notion of ethical fading and "bounded ethicality" challenges the notion that such awareness is always present in ethical dilemmas. 
As Tenbrunsel and Messick (2004, p. 204) assert, "Individuals do not "see" the moral components of an ethical decision, not so much because they are morally uneducated, but because psychological processes fade the "ethics" from an ethical dilemma.". The concept of bounded ethicality makes a similar argument. Bounded ethicality is derived from earlier research on the notion of bounded rationality in which it is argued that people are cognitively limited (Simon, 1957). That is, people are limited in updating their beliefs continuously and can thus not always take perfect and accurate decisions. Rather, many of our decisions are biased in ways that we make use of many heuristics (rules of thumbs) and stereotypical beliefs that often have an intuitive character. In a similar vein, bounded ethicality describes the impact of psychological biases that lead people to engage in unethical behavior that does not respond to their own normative beliefs (Banaji and Bhaskar, 2000; Banaji et al., 2003; Chugh et al., 2005). In this process, people develop or adhere to cognitions (biases, beliefs) that make them feel legitimate to engage in behaviors that they would deem inappropriate and wrong if they would reflect upon it or would be aware of it. In other words, bounded ethicality leads people to be able to see themselves as ethical persons while making unethical decisions, thereby reducing or even elimination their moral awareness (Chugh, Bazerman, \& Banaji, 2005). For this reason, we need to understand factors that influence people's ethical awareness in implicit and indirect ways.

Mulder and Nelissen focus on the awareness of norms that prescribe ethical behavior by means of rules. Such rules (i.e., to cooperate) are often installed to prevent egoistic behavior if self-interested behavior conflicts with the welfare of the collective. Mulder and Nelissen show across three experimental studies that installing such rules may make personal moral norms to cooperate salient, but only when the rule is installed by a leader who is self-sacrificing rather than self-interested. Moreover, they also show that self-sacrificing leaders can install rules that increase cooperation without the need for a perfectly operating monitoring system, suggesting that such moral norms result in voluntary cooperation.

Ruedy and Schweitzer consider how mindfulness, an individual's awareness of his or her present experience, impacts ethical decision making. They demonstrate, first of all, that individuals high in mindfulness report that they are more likely to act ethically, are more likely to value upholding ethical standards, and are more likely to use a principled approach to ethical decision making (i.e., formalism). In a subsequent study, they test this relationship with a novel behavioral measure of unethical behavior: the Carbonless Anagram Method (CAM). This study shows that among participants who cheated, individuals high in mindfulness cheated less. These results thus demonstrate the important role of mindfulness in ethical decision making.

Finally, Gino and Pierce focus on helping or hurting others as a function of the relationship with a beneficiary or victim of dishonest acts and how they evaluate the ethics in it. In two laboratory experiments, they investigate whether perceived inequity from wealth that is assigned randomly or based on performance leads individuals to cross ethical boundaries through helping or hurting others. The results show that people attempt to reduce inequity by dishonest helping or hurting behavior. Furthermore, a final experiment shows that the awareness of moral aspects of helping or hurting others varies as a function of whether such acts are for the sake of equity or not: people find helping or hurting others less wrong when it restores equity than when this is not the case.

\section{Managing distrust}

Ethical failures often go hand in hand with a decline of trust. The occurrence of distrust is a severe problem and requires that we understand how unethical behaviors can be dealt with in ways that trust is restored. Indeed, when ethical failures emerge integrity suffers (Paine, 1994). For this reason, a lack of ethics may erode trust. In circumstances of ethical failures, the stakes are thus high because trust is an important antecedent of organizational performance (De Cremer et al., 2001). Companies that manage ethical failures well tend to preserve or even promote a trustworthy reputation (Pillutla et al., 2009). Those companies that take a long time to respond to an ethical crisis may be permanently hurt in terms of their perceived trustworthiness. Despite the fact that "a more elusive benefit of ethics in organizations is trust" (Treviño, 2007, p. 49), the literature on 
business ethics has devoted little attention to this issue (see also De Cremer et al., 2010b). Therefore, a specific focus on dealing with the aftermath of ethical failures is much needed (De Cremer et al., 2010a).

Desmet, De Cremer, and Van Dijk look in greater detail at the processes involved in the repair of trust in economic exchange relations. Because transgressions in these relations often result in financial harm for one party, a common restorative approach consists of the transgressor paying a financial compensation to the victim; either voluntarily, or following coercion by a third party (cf. litigation). The authors studied the impact of financial compensations on victims' trust toward the transgressor and examined whether the size of the compensation is relevant to this process. Experimental data showed that larger compensations foster more trust, but only when the compensation is provided voluntarily.

\section{Conclusion}

In the wake of the current financial crisis, it has once again been pointed out that business and organizations not only need to be able to eliminate or prevent unethical deeds but also manage and deal with the aftermath of ethical failures. To do so effectively, requires an approach that heightens our understanding of how leaders can tackle such circumstances in more effective ways, how awareness of what is appropriate and right works, and how the resulting distrust can be managed in repairing ways. In this issue, series of papers is presented focusing on the psychological underpinnings of these issues. In total, these papers will not only advance our knowledge in the field of behavioral business ethics but will also inspire those working in the field and being responsible for developing interventions aimed at promoting ethical work climates.

\section{References}

Adams, J. S., A. Taschchian and T. H. Shore: 2001, 'Codes of Ethics as Signals for Ethical Behavior', Journal of Business Ethics 29, 199-211.

Banaji, M. R., M. Bazerman and D. Chugh: 2003, 'How (Un)Ethical Are You?', Harvard Business Review 81, 56-64.
Banaji, M. R. and R. Bhaskar: 2000, 'Implicit Stereotypes and Memory: The Bounded Rationality of Social Beliefs', in D. L. Schacter and E. Scarry (eds.), Memory, Brain, and Belief (Harvard University Press, Cambridge, MA), pp. 139-175.

Bazerman, M. H. and M. R. Banaji: 2004, 'The Social Psychology of Ordinary Ethical Failures', Social Justice Research 17, 111-115.

Brown, M., L. K. Treviño and D. Harrison: 2005, 'Ethical Leadership: A Social Learning Perspective for Construct Development and Testing', Organizational Behavior and Human Decision Processes 97, 117-134.

Chugh, D., M. R. Banaji and M. H. Bazerman: 2005, 'Bounded Ethicality as a Psychological Barrier to Recognizing Conflicts of Interest', in D. A. Moore, M. Cain, G. Loewenstein and M. H. Bazerman (eds.), Conflicts of Interest: Problems and Solutions from Law, Medicine, and Organizational Settings (Cambridge University Press, London).

De Cremer, D.: 2009, 'Being Unethical or Becoming Unethical: An Introduction', in D De Cremer (ed.), Psychological Perspectives on Ethical Behavior and Decision Making (Information Age Publishing, Greenwich), pp. 3-13.

De Cremer, D.: 2010, 'On the Psychology of Preventing and Dealing with Ethical Failures: A Behavioral Ethics Approach', in M Schminke (ed.), Managerial Ethics (New York, Routledge).

De Cremer, D., D. Mayer and M. Schminke: 2010a, 'On Understanding Ethical Behaviour and Decision Making: A Behavioral Business Ethics Approach', Business Ethics Quarterly 20, 1-6.

De Cremer, D., M. Snyder and S. Dewitte: 2001, 'The Less I trust, the Less I contribute (or not)? The Effects of Trust, Accountability and Self-Monitoring in Social Dilemmas', European Journal of Social Psychology 31, 93107.

De Cremer, D. and A. E. Tenbrunsel: forthcoming, Behavioral Business Ethics: Shaping an Emerging Field. Taylor and Francis: New York.

De Cremer, D., E. van Dijk and M. Pillutla: 2010b, 'Explaining Unfair Offers in Ultimatum Games and Their Effects on Trust: An Experimental Approach', Business Ethics Quarterly 20, 107-126.

Dinehart, J., D. Moberg and R. Duska: 2001, The Next Phase of Business Ethics: IntegratingPsychology and Ethics (Elsevier Science, Oxford).

Ferrell, C., J. Fraedrich and L. Ferrell: 2008, Business ethics: Ethical decision making and cases, 7th Edition (Houghton Mifflin, Boston, MA).

Fiske, A. P.: 1992, 'The Four Elementary Forms of Sociality: Framework for a Unified Theory of Social Relations', Psychological Review 99, 689-723. 
Jones, T. M.: 1991, 'Ethical Decision Making by Individuals in Organizations: An Issue-Contingent Model', Academy of Management Review 16, 366-395.

Kanungo, R. N.: 2001, 'Ethical Values of Transactional and Transformational Leaders', Canadian Journal of Administrative Sciences 18, 257-265.

Ludwig, D. C. and C. D. Longenecker: 1993, 'The Balsheba Syndrome: The Ethical Failure of Successful Leaders', Journal of Business Ethics 12, 265-273.

Mayer, D. M., M. Kuenzi, R. Greenbaum, M. Bardes and R. Salvador: 2009, 'How Low Does Ethical Leadership Flow? Test of a Trickle-Down Model', Organizational Behavior and Human Decision Processes 108, 1-13.

Messick, D. M. and M. H. Bazerman: 1996, 'Ethical Leadership and the Psychology of Decision Making', Sloan Management Review 37, 9-22.

Messick, D. M. and A. E. Tenbrunsel (eds.): 1996, Codes of Conduct: Behavioral Research into Business Ethics (Russell Sage, New York).

Morris, C. G. and A. A. Maisto: 2001, Psychology: An introduction, 11th Edition (Prentice Hall, Upper Saddle River).

Paine, L. S.: 1994, Managing for Corporate Integrity. Harvard Business Review, 106-117.

Pillutla, M., J. K. Murnighan and D. De Cremer: 2009, Transgressions as Opportunities to Build Trust, Unpublished manuscript (London Business School, UK).

Schwartz, A.: 2001, 'The Nature of The Relationship Between Corporate Codes of Ethics And Behavior', Journal of Business Ethics 32, 247-262.

Simon, H. A.: 1957, Models of Man (Wiley, New York).

Tenbrunsel, A. E. and D. M. Messick: 2004, 'Ethical Fading: The Role of Self-Deception in Unethical Behavior', Social Justice Research 17, 223-236.

Tenbrunsel, A. E. and K. Smith-Crowne: 2008, 'Ethical Decision Making: Where We've Been and Where We're Going', The Academy of Management Annals 2, 545-607.
Treviño, L. K.: 2007, Managing Business Ethics: Straight talk About How to do It Right, 4th Edition (Wiley, New York).

Trevino, L. K. and G. R. Weaver: 1994, 'Business Ethics: One Field or Two?', Business Ethics Quarterly 4, 113-128.

Treviño, L. K., G. R. Weaver and S. J. Reynolds: 2006, 'Behavioral Ethics in Organizations: A Review', Journal of Management 32, 951-990.

Walumbwa, F. O. and J. Schaubroeck: 2009, 'Leader Personality Traits and Employee Voice Behavior: Mediating Roles of Ethical Leadership and Work Group Psychological Safety', Journal of Applied Psychology 94, 1275-1286.

Weaver, G.: 2001, 'Ethics Programs in Global Businesses: Culture's Role in Managing Ethics', Journal of Business Ethics 30, 3-15.

David De Cremer and Marius van Dijke Department of Business-Society Management, Rotterdam School of Management, Erasmus Centre of Behavioural Ethics,

Erasmus University Rotterdam, P. O. Box 1738, 3000 DR Rotterdam, Netherlands E-mail:ddecremer@rsm.nl URL: www.erim.nl/behaviouralethics

David De Cremer London Business School, London, U.K.

Ann E. Tenbrunsel Mendoza College of Business, Notre Dame University, Notre Dame, IN, U.S.A. 